\title{
Spectroscopic characterization on the neutral excited state and cationic ground state of styrene
}

Zehua Qu, Zhengbo Qin a), Hui Wang, Yangdi Ren, Xianfeng Zhenga), Guanxin Yao, Xianyi Zhang, and Zhifeng Cui

\begin{abstract}
The spectroscopic properties of styrene have been investigated via resonance-enhanced multiphoton ionization (REMPI) and slow electron velocity-map imaging (SEVI) methods. Vibrational frequencies in the first excited state of neutral $\left(S_{1}\right)$ and ground electronic state of cation $\left(D_{0}\right)$ have been accurately measured. From the one-color REMPI spectrum of styrene, the $\mathrm{S}_{1} \leftarrow \mathrm{S}_{0}$ electron transition energy is determined as $34729 \pm 3 \mathrm{~cm}^{-1}$. Most low-frequency vibrations of $S_{1}$ state are unambiguously identified with the aid of calculated results at TD-B3LYP/6-311++G(d, p) level. Some controversially high-frequency vibrational modes of $S_{1}$ state are reassigned in comparison with theoretical results. The SEVI spectra taken via various $\mathrm{S}_{1}$ intermediate levels provide the detailed vibrational structures of $\mathrm{D}_{0}$ state and directly yield the accurate adiabatic ionization potential (IP) of $68267 \pm 6 \mathrm{~cm}^{-1}$. The vibrational frequencies of the $\mathrm{D}_{0}$ state calculated at the B3LYP/6-311++G(d, p) level are in excellent agreement with the experimental results to aid us assigning some high-frequency vibrational modes. In addition, photoelectron angular distributions (PADs) in the twostep transitions are presented, suggesting no apparent threshold shape resonance is investigated in the ionization of styrene without unambiguous drastic changes in PADs.
\end{abstract}

Key words: Velocity-map imaging, Time-of-flight, REMPI, Styrene 


\section{Introduction}

Styrene, the simplest molecule containing both an aromatic ring and a double bond, is widely used in different areas of industrial, environmental and biological processes [1,2]. It plays an essential role in the atmospheric oxidation reaction and the production of secondary organic aerosols $[3,4]$. In addition, styrene has been extensively studied as a prototype for ultrafast relaxation in many photochemical and photobiological processes [5]. The study on the structures and vibrations of styrene molecule in the specifically electronic state can help us to understand the molecular properties, and hence has become an increasing active field.

The investigations of neutral ground state $\left(\mathrm{S}_{0}\right)$ of styrene have extensively been performed via different spectroscopic [6-12] and theoretical [12-18] methods. The discrepancy about the structure of the $\mathrm{S}_{0}$ state exists in previous works. These studies, such as Suzuki [6] using electronic absorption spectra, Grassian et al. [7] using one-color time-of-flight mass spectrometry (TOFMS), Britton et al. [13] and Granadino-Roldán et al.[12] using theoretical approaches conclude that the styrene molecule is planar in $\mathrm{S}_{0}$ state. On the other hand, the results from NMR spectroscopy experiment [8] and theoretical calculations using HF/4-31G, HF/ 6-31G* and MP2/6-311G** method [14-16] suggest non-planar property of styrene in $\mathrm{S}_{0}$ state, with a deviating from planarity by $\sim 10.5^{\circ}$. As for the neural first excited $\left(\mathrm{S}_{1}\right)$ state of styrene, strictly planar structure is investigated by resonant-enhanced multiphoton ionization [19-22] and fluorescence [23-28] spectra as well as semi-empirical $[17,18]$ and ab initio $[29,30]$ calculations, indicating a fairly deep well in the torsional degree of freedom. In addition, ionic properties of styrene have also been investigated by zero kinetic energy (ZEKE) spectroscopy [31,32]. Still, a more detailed vibrational structure for the ground and excited states in neutral and the ground state in cation of styrene needs to be investigated to extend spectra far from low-frequency region.

Recently, pump-probe laser photoelectron spectroscopy is one of most potential tool for probing the dynamics of the excited state and locating ion internal structure. In conjunction with slow electron velocitymap imaging (SEVI) technique, they extended the field to medium and large biological and photochemistry related organic molecules by virtue of excellent collection efficiency and high energy resolution [33]. One of merit for this technique is that the information on the photoelectron angular distribution can be extracted from SEVI.

In this work, one-color resonant two-photon ionization (1C-R2PI) spectrum within $\sim 2000 \mathrm{~cm}^{-1}$ upon the $\mathrm{S}_{1} \leftarrow \mathrm{S}_{0}$ electronic transition and the two-color resonant two-photon ionization (2C-R2PI) SEVI spectra of styrene cation have been reported. The precise adiabatic ionization potential (IP) and vibrational frequencies of styrene has been deduced from the spectra. SEVI spectra are obtained by ionizing through the intermediate vibrational level in the $S_{1}$ state to obtain more information about the active vibrational modes 
in $\mathrm{D}_{0}$ state. Ab initio and density functional theory (DFT) calculations have also been performed to predict the electronic transition energies, vibrational frequencies, to provide a clear-cut assignment of the vibrational spectra of styrene and its cation.

\section{Experimental and computational methods}

The experimental apparatus used for this study has been previously described [34], and only a brief description is given here. The styrene (98\%) purchased from J\&K Scientific was used without any purification. The molecular beam was supersonically expanded into vacuum chamber through a pulsed valve of orifice diameter $0.5 \mathrm{~mm}$ (Parker, General Valve series 9) running at $10 \mathrm{~Hz}$. The backpressure of the pulse valve was about 4 bar supplied with bubbling argon through a reservoir of styrene at room temperature. After collimation by the skimmer with a $0.5 \mathrm{~mm}$ diameter, the styrene beam entered the interaction region midway between the repeller and extractor plates. The excitation laser pulse was generated by frequency doubling of the dye laser output (Sirah) pumped by the third harmonic output of Nd:YAG laser (SpectraPhysics). The ionization laser pulse was generated by frequency-doubling of the output of another dye laser (ND6000, Contiunuum) pumped by another Nd:YAG laser (Powerlite Precision II, Continuum). Coumarin 153, Rhodamine 590, Pyrromethene 597, and Rhodamine 610 were used to acquire the required dye laser wavelengths. The laser bandwidth was approximately $0.1 \mathrm{~cm}^{-1}$, and the duration of the laser pulse was about 8 ns.

The 1C-R2PI experiment was performed near the $\mathrm{S}_{1} \leftarrow \mathrm{S}_{0}$ transition of styrene by using a tunable frequency-doubling dye laser (Sirah) pumped by Nd:YAG laser (Spectra-Physics). Energy of $\sim 40 \mu \mathrm{J} /$ pulse was held without focusing. The produced ions were perpendicularly accelerated by time-of-flight lenses. Ion signals were measured and analyzed by a multichannel scaler (MCS, SRS, SR245). The time-gated mass spectra were accumulated for 100 laser shots for each wavelength. And wavelength was scanned at $0.3 \mathrm{~cm}^{-1}$ spacing. In the $2 \mathrm{C}-\mathrm{R} 2 \mathrm{PI}$ experiment, the pulse energy of the excitation laser was held below $10 \mu \mathrm{J}$ to prevent the 1C-R2PI process. The photoelectron signal was practically absent when only one of two laser pulses was applied to the system. Both laser pulses were linearly polarized with their E vectors perpendicular to the time-of-flight axis. The delay time between the excitation laser, the ionization laser and the pulse valve was controlled using two digital delay/pulse generators (DG535, SRS). Photoelectrons were accelerated along the time-of-flight axis in the velocity mapping condition and projected onto a home-made position-sensitive detector (50 mm diameter) coupled with a personal computer-interfaced CCD camera (Basler Scott, $782 \times$ 582 pixels) system in conjunction with the photo-counting mode software interface embedded in LabVIEW code. The SEVI images were taken at low electric field condition $(38 \mathrm{~V} / \mathrm{cm})$, and reconstructed through the BASEX program [35].

Geometry optimization and harmonic vibrational frequency calculations of styrene in the $\mathrm{S}_{0}, \mathrm{~S}_{1}$, and $\mathrm{D}_{0}$ 
states were all performed via the NWChem program package [36]. The carbon atoms of styrene around the ring are labeled 1-6 and the substitution is numbered as $\mathrm{C}_{4}-\mathrm{C}_{7}=\mathrm{C}_{8}$. For $\mathrm{S}_{0}$ and $\mathrm{D}_{0}$ states $\mathrm{B} 3 \mathrm{LYP} / 6-311++\mathrm{G}(\mathrm{d}$, p) method was applied [37], whereas the TD-B3LYP/6-311++G(d, p) method was employed for the $S_{1}$ state. The stationary points were characterized as the energy minimum by verifying that all the corresponding frequencies were real. The calculated vibrational frequencies were scaled by a certain factor to approximately correct the combined errors stemming from the basis-set incompleteness and vibrational anharmonicity.

\section{Results}

\section{Molecular geometries of styrene in the $S_{0}, S_{1}$, and $D_{0}$ states}

Optimized structural parameters and frequencies of styrene in the ground states $\left(\mathrm{S}_{0}\right.$ and $\left.\mathrm{D}_{0}\right)$ and the first excited state $\left(\mathrm{S}_{1}\right)$ are listed in Table 1 , in comparison to the experimental frequencies. Fig. 1 shows the diagram of styrene molecule structure with the $\mathrm{CC}$ bond lengths (in $\AA$ ) of $\mathrm{S}_{0}, \mathrm{~S}_{1}$, and $\mathrm{D}_{0}$ states in different fonts. The bold, italic, and underline types represent $S_{0}, S_{1}$, and $D_{0}$ states, respectively. Most vibrational frequencies predicted at this method agree well with experiment within the range of $\pm 10 \mathrm{~cm}^{-1}$ except for mode 8 and 9 with a slight deviation of $19 \mathrm{~cm}^{-1}$. The gap in vibrational frequency between theory and experiment is much less than that obtained from the torsional structure in $\mathrm{S}_{0}$ state of styrene [16].

The $S_{1} \leftarrow S_{0}$ transition is subjected to the $\pi^{*} \leftarrow \pi$ excitation of the benzene ring due to the population of antibonding orbital. As expected, the structure of $S_{1}$ state is also planar. When it is excited to the $S_{1}$ state, the lengths of ring $\mathrm{CC}$ bonds are all lengthened, except that the $\mathrm{C}_{2}-\mathrm{C}_{3}$ and $\mathrm{C}_{5}-\mathrm{C}_{6}$ bonds are shorten by 0.002 and $0.019 \AA$. The $\mathrm{CH}$ bond lengths are almost unchanged upon excitation. In addition, the $\mathrm{C}_{7}=\mathrm{C}_{8}$ bond is slightly lengthened and the $\mathrm{C}_{4}-\mathrm{C}_{7}$ bond is shortened slightly.

The same as $S_{0}$ and $S_{1}$ states, the $D_{0}$ state is also found to be strictly planar. On the $D_{0} \leftarrow S_{1}$ excitation, the benzene ring is deformed: the $\mathrm{C}_{2}-\mathrm{C}_{3}, \mathrm{C}_{3}-\mathrm{C}_{4}$ and $\mathrm{C}_{1}-\mathrm{C}_{6}$ bonds are shortened, while the $\mathrm{C}_{1}-\mathrm{C}_{2}$ and $\mathrm{C}_{4}-\mathrm{C}_{5}$ bonds are lengthened. The aromatic character of the ring is considerably expanded in this state in comparison to the $\mathrm{CC}$ bond lengths in the neural ground state. The $\mathrm{CH}$ bonds are nearly unchanged upon ionization. The bond lengths of the $\mathrm{C}_{7}=\mathrm{C}_{8}$ and $\mathrm{C}_{4}-\mathrm{C}_{7}$ bonds are changed from 1.401 and $1.407 \AA$ in the $\mathrm{S}_{1}$ state to 1.375 and $1.423 \AA$ in the $\mathrm{D}_{0}$ state for styrene, respectively. 


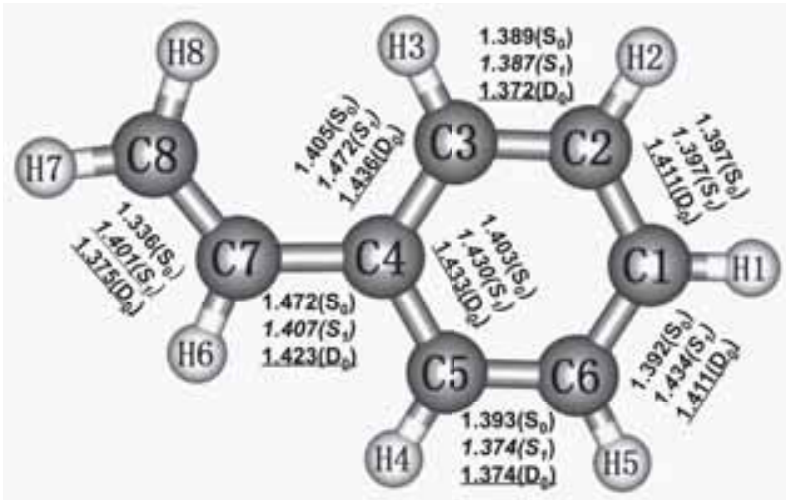

Fig. 1. Geometries and labeling of the atoms for styrene at neural ground state $\mathrm{S}_{0}$, ionic ground state $\mathrm{D}_{0}$ using the optimized B3LYP/6-311++G(d, p) structure, and first excited state $S_{1}$ at the TD-B3LYP/6-311++G(d, p) level. The Bold, italic, and underline types represent $\mathrm{S}_{0}, \mathrm{~S}_{1}$, and $\mathrm{D}_{0}$ states, respectively. Bond distances are given in $\AA$.

\section{1C-R2PI spectrum of styrene}

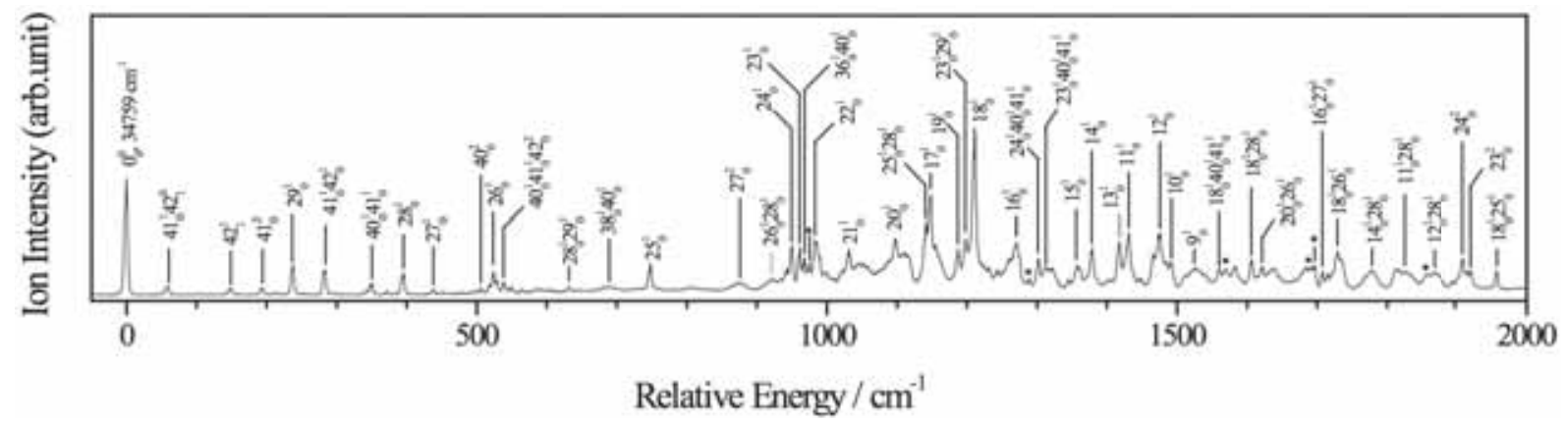

Fig. 2. 1C-R2PI spectrum of styrene within $\sim 2000 \mathrm{~cm}^{-1}$ upon the $\mathrm{S}_{1} \leftarrow \mathrm{S}_{0}$ electronic transition. The origin band of styrene is ionized at $34759 \mathrm{~cm}^{-1}$. * denotes unassigned bands.

Fig. 2 shows the 1C-R2PI spectrum of styrene in the range of $\sim 2000 \mathrm{~cm}^{-1}$ upon the $\mathrm{S}_{1} \leftarrow \mathrm{S}_{0}$ transition. The band origin of this vibronic spectrum appears at $34759 \mathrm{~cm}^{-1}$ in accordance with previous experimental investigations [20,27,28]. In term of reported assignments [19-28], the bands at 395, 748 and $1149 \mathrm{~cm}^{-1}$ are readily identified as vibrational modes 28,25 and 17, respectively, which mainly involve the in-plane bending and stretching motions of $\mathrm{C}_{4}-\mathrm{C}_{7}$ and ring.

Transition $29_{0}{ }^{1}$ resulting from the characteristic in-plane bending motion of the $\mathrm{C}_{4}-\mathrm{C}_{7}$ single bond appears at $238 \mathrm{~cm}^{-1}$. The intense band at $1211 \mathrm{~cm}^{-1}$ is recognized as mode 18 , which is related to the in-plane $\mathrm{C}_{4}-\mathrm{C}_{7}$ single bond stretching vibration. Those peaks at 438 and $524 \mathrm{~cm}^{-1}$ are assigned to transitions $27_{0}{ }^{1}$ and $26_{0}{ }^{1}$, corresponding to the in-plane $\mathrm{C}=\mathrm{C}$ double bond bending and ring deformation vibrations. The combination bands $41_{0}{ }^{1} 42_{1}{ }^{0}, 41_{0}{ }^{1} 42_{0}{ }^{1}$ and $40_{0}{ }^{1} 41_{0}{ }^{1}$ are relevant to the out-of-plane vibrational modes, which appear at 59, 283 and $350 \mathrm{~cm}^{-1}$, respectively. The bands at 194 and $506 \mathrm{~cm}^{-1}$ are ascribed to the two-quantum transition $41_{0}^{2}$ and $40_{0}^{2}$, respectively. The frequencies of $v_{40}, v_{41}$ and $v_{42}$ modes in $S_{1}$ state are thus determined to be 253,97 and $186 \mathrm{~cm}^{-1}$. A weak band at $149 \mathrm{~cm}^{-1}$ is assigned to the hot band $42{ }_{1}{ }^{1}$.

To re-examine above assignments, we performed theoretical calculation at TD-B3LYP /6-311++G(d, p) level for the $S_{1}$ state of styrene. The calculated frequencies listed in Table 1 are in reasonable agreement with the above assignments. We suggest a possible reassignment of some of high-frequency modes for $\mathrm{S}_{1}$ state. The bands appearing at 950,961,983,1031, 1098, 1187 and $1357 \mathrm{~cm}^{-1}$ are assigned to the $24_{0}{ }^{1}, 23_{0}{ }^{1}, 22_{0}{ }^{1}$, 
$21_{0}{ }^{1}, 20_{0}{ }^{1}, 19_{0}^{1}$ and $15_{0}^{1}$ transitions, respectively, which mainly involve the in-plane ring deformation and $\mathrm{CH}$ bond bending. Those at 1271 and $1525 \mathrm{~cm}^{-1}$ are identified as modes 16 and 9 , corresponding to the inplane motion of $\mathrm{C}=\mathrm{C}$ double bond. Transition $14_{0}{ }^{1}$ resulting from the characteristic in-plane scissoring motion of the $\mathrm{CH}_{2}$ group appears at $1379 \mathrm{~cm}^{-1}$. The peaks at 1475 and $1492 \mathrm{~cm}^{-1}$ correspond to the $12_{0}{ }^{1}$ and $10_{0}{ }^{1}$ transitions, which are related to the in-plane $\mathrm{C}_{4}-\mathrm{C}_{7}$ stretching vibrations. The bands at 1417 and 1431 $\mathrm{cm}^{-1}$ are assigned to the $13_{0}{ }^{1}$ and $11_{0}{ }^{1}$ transitions, respectively. These two transitions are involved in the ring stretching motion. All of the observed vibronic bands in the 1C-R2PI spectrum are summarized in Table 2, along with the new possible assignments.

\section{SEVI spectra via the $S_{1}-S_{0}$ origin}

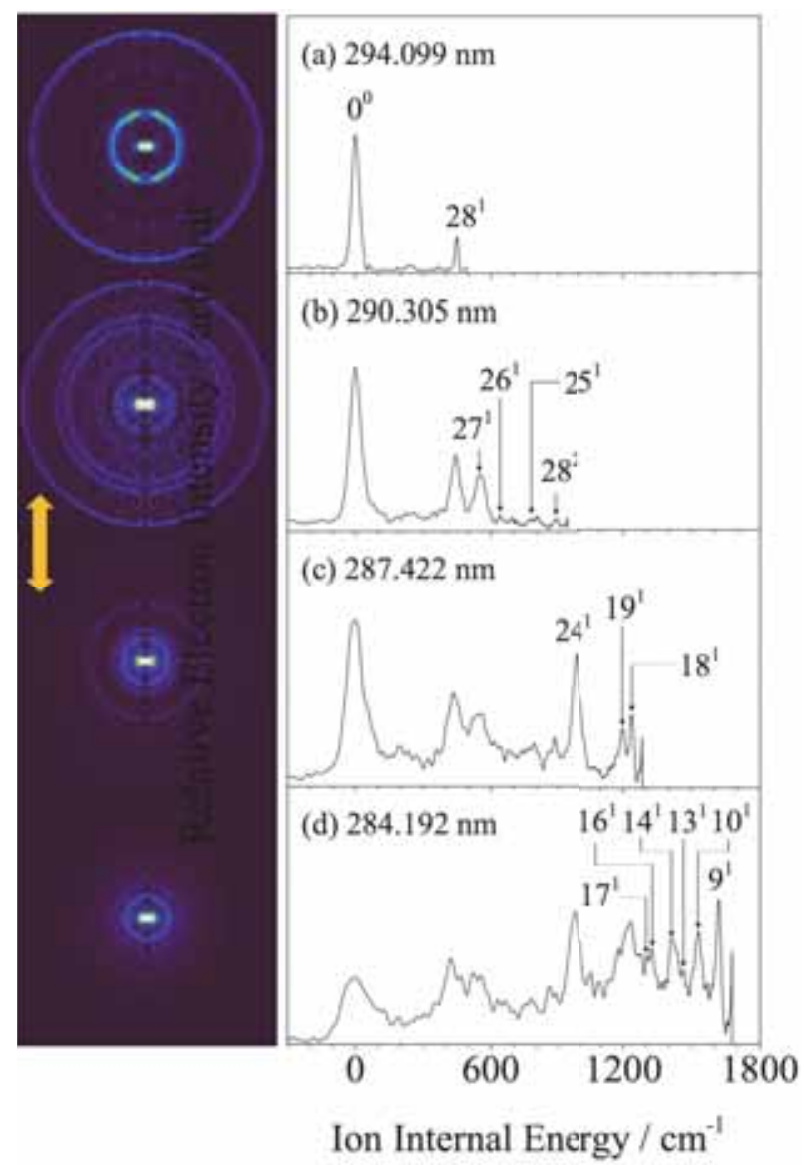

Fig. 3. 2C-R2PI SEVI images (left column) and corresponding spectra (right column) following the ionization of styrene in the 000 level in $S_{1}$, recorded with the probe wavelength set to (a) $294.099 \mathrm{~nm}$, (b) $290.305 \mathrm{~nm}$, (c) $287.422 \mathrm{~nm}$, (d) 284.192 $\mathrm{nm}$. The photoelectron images are reconstructed images after inverse Abel transformation. The double arrow indicates the directions of the laser polarization.

Figs. 3a-d demonstrate SEVI spectra of styrene recorded at four different wavelengths via $\mathrm{S}_{1} 0_{0}{ }^{0}$ origin. The SEVI bands resulting from the active vibrations of the styrene cation are listed in Table 1, along with the calculated frequencies and possible assignments. In view of reported assignments [31,32], the pronounced features shifted from the $0^{0}$ band by $449,552,983$ and $1236 \mathrm{~cm}^{-1}$ corresponds to the $28^{1}, 27^{1}$, $24^{1}$ and $18^{1}$ transitions, respectively. The frequency for the transition $28^{2}$ is measured to be $895 \mathrm{~cm}^{-1}$. The weak peaks appearing at 644 and $779 \mathrm{~cm}^{-1}$ are assigned to the modes 26 and 25 . Transitions $28^{1}, 25^{1}$ and $18^{1}$ 
mainly involve the in-plane $\mathrm{C}_{4}-\mathrm{C}_{7}$ motion, whereas mode 27 results from the in-plane $\mathrm{C}=\mathrm{C}$ double bond bending vibration. Furthermore, modes 24 and 26 are related to the ring deformation.

Theoretical calculation was carried out at B3LYP/6-311++G(d, p) level in $\mathrm{D}_{0}$ state for vibrational assignment. All calculated vibrational frequencies of $\mathrm{D}_{0}$ state are listed in Table 1 for comparison. Clearly, most vibrational frequencies agree well with the experimental results except for mode 26 with a deviation from experiment by $-68 \mathrm{~cm}^{-1}$. The calculation suggests that the intense bands at 1194, 1410, 1530 and 1618 $\mathrm{cm}^{-1}$ are assigned to the $19^{1}, 14^{1}, 10^{1}$ and $9^{1}$ transitions. The weak bands at 1303,1325 and $1465 \mathrm{~cm}^{-1}$ are identified as vibrational modes 17,16 and 13 , respectively. Transitions $17^{1}, 14^{1}$ and $10^{1}$ mainly involve the in-plane $\mathrm{C}_{4}-\mathrm{C}_{7}$ motion, whereas modes 16 and 9 result from the in-plane $\mathrm{C}=\mathrm{C}$ double bond stretching vibration. And, modes 19 and 13 are related to the ring stretching and $\mathrm{CH}$ bond bending vibration.

\section{SEVI spectra via the low frequency vibrational transitions}
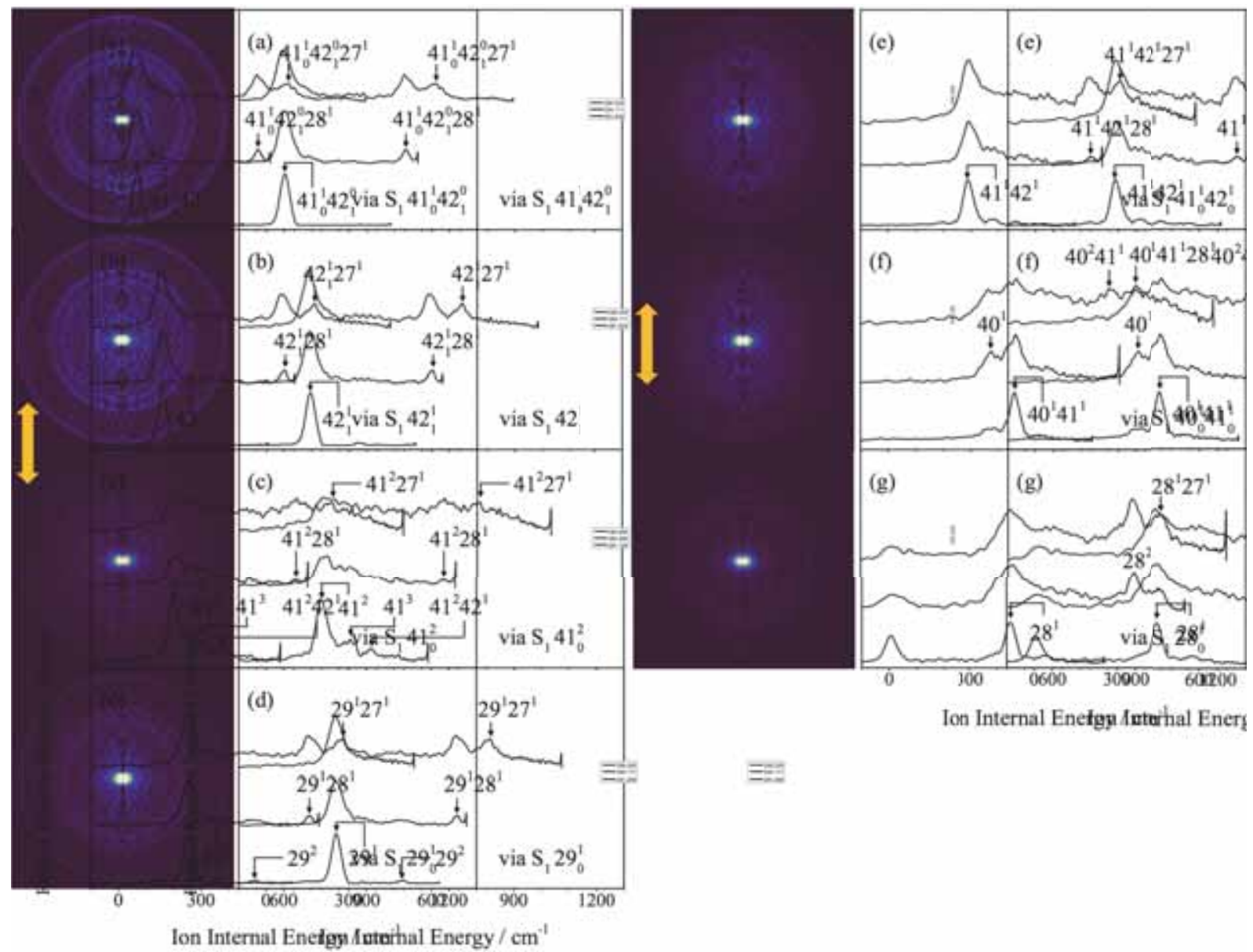

Ion Internal Enefgy /uturhal Enery

Fig. 4. 2C-R2PI SEVI images (left column) and corresponding spectra (right column) following the ionization of styrene via various intermediate states, recorded with the ionization wavelength set to $294.956 \mathrm{~nm}, 294.099 \mathrm{~nm}, 291.139 \mathrm{~nm}$. The photoelectron images are reconstructed images after inverse Abel transformation. The double arrow indicates the directions of the laser polarization.

As seen in Figs. 4a-f, when the low-frequency transitions $41_{0}^{1} 42_{1}{ }^{0}, 421^{1}, 41_{0}{ }^{2}, 290_{0}{ }^{1}, 41_{0}{ }^{1} 42_{0}{ }^{1}, 40_{0}{ }^{1} 41_{0}{ }^{1}$ in $\mathrm{S}_{1}$ state are used as the intermediate levels, the same transitions to $\mathrm{D}_{0}$ state of styrene display strong bands based on the $\Delta v=0$ propensity rule. An exception is shown in $4 \mathrm{~g}$ via $28_{0}{ }^{1}$ transition, which suggests a slightly worse Franck-Condon overlap along this vibrationally canonical coordinate. 
The strongest peak is observed at the ionic vibrational energy of $67 \mathrm{~cm}^{-1}$ via the $41_{0}{ }^{1} 42{ }_{1}{ }^{0}$ vibrational level in Fig. 4a is obviously recognized as the combination vibration $41^{1} 42_{1}{ }^{0}$. The 508 and $618 \mathrm{~cm}^{-1}$ bands are ascribed to combination vibrations $41^{1} 421^{0} 28^{1}$ and $41^{1} 421^{0} 27^{1}$, respectively. In Fig. 4b, as in the case of pump $421^{1}$ transition, three distinct bands observed at 159, 605 and $713 \mathrm{~cm}^{-1}$ are assigned to the $421^{1}$ vibration, combination vibrations $421_{1} 2^{2}$ and $421^{1} 27^{1}$. Fig. $4 \mathrm{e}$ shows the spectra taken via the $41_{0}{ }^{1} 42_{0}{ }^{1}$ vibrational level in the $\mathrm{S}_{1}$ state. The highest peak at $289 \mathrm{~cm}^{-1}$ corresponds to the combination vibrational band $41^{14} 42^{1}$ in the cationic ground state and other two bands at 732 and $842 \mathrm{~cm}^{-1}$ are due to the combination vibrations $41^{1} 42^{1} 28^{1}$ and $41^{1} 42^{1} 27^{1}$, respectively.

When the $S_{1} 41_{0}^{2}$ state is used as the intermediate level shown in Fig $4 \mathrm{c}$, the band at $200 \mathrm{~cm}^{-1}$ is assigned to the $41^{2}$ transition. The weak bands located at 381, 646 and $775 \mathrm{~cm}^{-1}$ are ascribed to combination transitions of the $41^{2} 42^{1}, 41^{2} 28^{1}$, and $41^{2} 27^{1}$, respectively. Since the transition $41^{1}$ is not observed directly in the SEVI spectra, its frequency is estimates by taking half of the overtone to yield a value of $100 \mathrm{~cm}^{-1}$. This is a reasonable approximation because $v_{41}$ appears harmonic in $S_{1}\left(194 \mathrm{~cm}^{-1}\right)$ and is not drastically different in frequency in the cation. Thus the small peak located at $305 \mathrm{~cm}^{-1}$ is ascribed to the three-quantum transition $41^{3}$. The $40^{1} 41^{1}$ combination vibration is easily recognized at $816 \mathrm{~cm}^{-1}$ in Fig. $4 \mathrm{f}$. The value of $v_{40}$ and $v_{42}$ can be determined to be 359 and $189 \mathrm{~cm}^{-1}$ due to the established value of $v_{41}$ and the observed combination bands $40^{14} 1^{1}$ and $41^{14} 2^{1}$. Therefore the peak located at $359 \mathrm{~cm}^{-1}$ is assigned to $40^{1}$ transition. Two weak bands of $40^{2} 41^{1}$ and $40^{1} 41^{1} 28^{1}$ are observed at 803 and $901 \mathrm{~cm}^{-1}$, respectively.

The SEVI spectrum obtained through the $290^{1}$ vibronic level $\left(238 \mathrm{~cm}^{-1}\right)$ clearly shows that the corresponding $29^{1}$ vibrational band in the $\mathrm{D}_{0}$ state is located at $254 \mathrm{~cm}^{-1}$, as shown in Fig. $4 \mathrm{~d}$. Its first weakly overtone $29^{2}$ vibration is found at $502 \mathrm{~cm}^{-1}$, while the $29^{1} 28^{1}$ and $29^{1} 27^{1}$ bands can be easily identified at 696 and $816 \mathrm{~cm}^{-1}$, respectively. As shown in Fig. $4 \mathrm{~g}$, the frequency of mode 28 is measured to be $449 \mathrm{~cm}^{-1}$, and the two-quantum transition 282 is found at $895 \mathrm{~cm}^{-1}$. The peak at $997 \mathrm{~cm}^{-1}$ is assigned to the combination band $28^{12} 7^{1}$. 
Table 1. Vibrational frequencies of styrene in the $S_{0}, S_{1}$ and $D_{0}$ states (in $\mathrm{cm}^{-1}$ ).

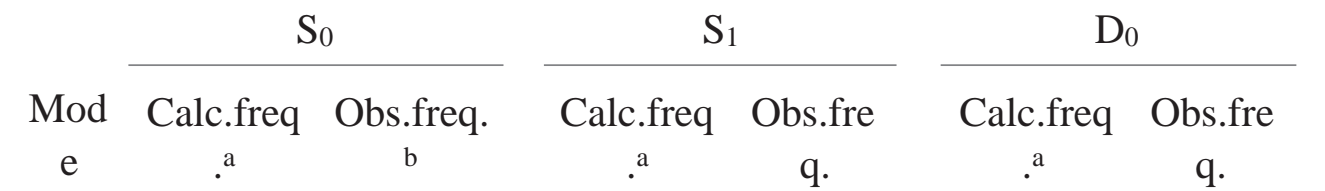

In plane modes $\left(a^{\prime}\right.$ symmetry)

\begin{tabular}{|c|c|c|c|c|c|c|c|}
\hline 1 & 3088 & 3085 & 3108 & & 3116 & & $\mathrm{CH}_{2}$ stretch \\
\hline 2 & 3057 & 3060 & 3056 & & 3078 & & ring $\mathrm{CH}$ stretch \\
\hline 3 & 3049 & 3055 & 2995 & & 3073 & & ring $\mathrm{CH}$ stretch \\
\hline 4 & 3041 & 3041 & 3006 & & 3066 & & ring $\mathrm{CH}$ stretch \\
\hline 5 & 3032 & 3035 & 2983 & & 3057 & & ring $\mathrm{CH}$ stretch \\
\hline 6 & 3025 & 3027 & 2977 & & 3053 & & ring $\mathrm{CH}$ stretch \\
\hline 7 & 3011 & 3008 & 2965 & & 3032 & & $\mathrm{CH}_{2}$ stretch \\
\hline 8 & 2999 & 2980 & 2826 & & 3022 & & vinyl $\mathrm{CH}$ stretch \\
\hline 9 & 1649 & 1630 & 1528 & 1525 & 1629 & 1618 & $\mathrm{C}=\mathrm{C}$ stretch; $\mathrm{C}_{4}-\mathrm{C}_{7}$ bend \\
\hline 10 & 1606 & 1601 & 1473 & 1492 & 1539 & 1530 & ring stretch; $\mathrm{C}_{4}-\mathrm{C}_{7}$ stretch \\
\hline 11 & 1581 & 1576 & 1409 & 1431 & 1513 & & ring stretch \\
\hline 12 & 1494 & 1494 & 1436 & 1475 & 1473 & & $\mathrm{C}_{4}-\mathrm{C}_{7}$ stretch; ring def. \\
\hline 13 & 1450 & 1450 & 1399 & 1417 & 1454 & 1465 & ring stretch; $\mathrm{CH}$ bend \\
\hline 14 & 1422 & 1412 & 1352 & 1379 & 1421 & 1410 & $\mathrm{CH}_{2}$ scissor; $\mathrm{C}_{4}-\mathrm{C}_{7}$ stretch \\
\hline 15 & 1334 & 1334 & 1341 & 1357 & 1368 & & $\mathrm{CH}$ bend \\
\hline 16 & 1317 & 1317 & 1257 & 1271 & 1324 & 1325 & ring stretch; $\mathrm{C}=\mathrm{C}$ bend \\
\hline 17 & 1290 & 1296 & 1138 & 1149 & 1281 & 1303 & ring stretch; $\mathrm{C}_{4}-\mathrm{C}_{7}$ bend \\
\hline 18 & 1199 & 1202 & 1216 & 1211 & 1232 & 1236 & $\mathrm{C}_{4}-\mathrm{C}_{7}$ stretch \\
\hline 19 & 1179 & 1182 & 1149 & 1187 & 1194 & 1194 & ring $\mathrm{CH}$ bend \\
\hline 20 & 1157 & 1156 & 1129 & 1098 & 1163 & & ring $\mathrm{CH}$ bend \\
\hline 21 & 1087 & 1083 & 1033 & 1031 & 1103 & & ring $\mathrm{CH}$ bend \\
\hline 22 & 1033 & 1033 & 848 & 983 & 1023 & & ring def.; vinyl $\mathrm{CH}$ bend \\
\hline 23 & 1018 & 1021 & 963 & 961 & 995 & & ring def.; vinyl $\mathrm{CH}$ bend \\
\hline 24 & 993 & 995 & 922 & 950 & 980 & 983 & ring def. \\
\hline 25 & 770 & 775 & 670 & 748 & 770 & 779 & $\mathrm{C}_{4}-\mathrm{C}_{7}$ stretch; ring stretch \\
\hline 26 & 620 & 620 & 562 & 524 & 576 & 644 & ring def. \\
\hline
\end{tabular}




\begin{tabular}{|c|c|c|c|c|c|c|c|}
\hline 27 & 549 & 555 & 511 & 438 & 547 & 552 & $\mathrm{C}=\mathrm{C}$ bend; ring stretch \\
\hline 28 & 438 & 436 & 393 & 395 & 442 & 449 & $\mathrm{C}_{4}-\mathrm{C}_{7}$ bend; ring stretch \\
\hline 29 & 229 & $228^{d}$ & 206 & 238 & 237 & 254 & $\mathrm{C}_{4}-\mathrm{C}_{7}$ bend \\
\hline
\end{tabular}

Out of plane modes(a" symmetry)

\begin{tabular}{|c|c|c|c|c|c|c|c|}
\hline 30 & 1007 & $992^{c}$ & 836 & & 1004 & & $\mathrm{C}=\mathrm{C}$ torsion \\
\hline 31 & 980 & $985^{\mathrm{c}}$ & 937 & & 1009 & & ring $\mathrm{CH}$ bend \\
\hline 32 & 964 & $970^{c}$ & 927 & & 995 & & ring $\mathrm{CH}$ bend \\
\hline 33 & 912 & 909 & 749 & & 965 & & $\mathrm{CH}_{2}$ wag \\
\hline 34 & 910 & $909^{c}$ & 806 & & 947 & & ring $\mathrm{CH}$ bend \\
\hline 35 & 832 & 841 & 645 & & 805 & & ring $\mathrm{CH}$ bend \\
\hline 36 & 781 & 783 & 711 & & 639 & & ring $\mathrm{CH}$ bend; $\mathrm{C}_{4}-\mathrm{C}_{7}$ bend \\
\hline 37 & 694 & 699 & 518 & & 793 & & ring $\mathrm{CH}$ bend \\
\hline 38 & 641 & $640^{c}$ & 431 & & 513 & & $\mathrm{C}_{4}-\mathrm{C}_{7}$ bend; ring $\mathrm{CH}$ bend \\
\hline 39 & 437 & $433^{c}$ & 383 & & 386 & & ring puckering \\
\hline 40 & 402 & $399^{d}$ & 255 & 253 & 367 & 359 & ring def. \\
\hline 41 & 199 & $199^{d}$ & 96 & 97 & 96 & 100 & $\mathrm{C}_{4}-\mathrm{C}_{7}$ bend \\
\hline 42 & 32 & $38^{\mathrm{d}}$ & 191 & 186 & 189 & 188 & $\mathrm{C}_{4}-\mathrm{C}_{7}$ torsion \\
\hline
\end{tabular}

${ }^{a}$ Mode 1-8 frequencies scaled by 0.96 , mode $9-42$ frequencies scaled by 0.98

b Reference 12

${ }^{\mathrm{c}}$ Reference 9

d Reference 24

Table 2. A possible new assignment of the 1C-R2PI spectrum of styrene

\begin{tabular}{|c|c|c|c|c|c|c|}
\hline $\begin{array}{l}\text { Expt./ } \\
\mathrm{cm}^{-1}\end{array}$ & Assignment ${ }^{\mathrm{a}}$ & Assignment ${ }^{\mathrm{b}}$ & $\begin{array}{l}\text { New } \\
\text { assignment }\end{array}$ & Assignment $^{\mathrm{a}}$ & Assignment $^{\mathrm{b}}$ & New assignment \\
\hline 0 & $0_{0}{ }^{0}$ & $0_{0}^{0}$ & $0_{0}^{0}$ & 1232 & & $24_{0}{ }^{1} 41_{0}{ }^{1} 42_{0}{ }^{1}$ \\
\hline 59 & $410^{1} 421^{0}$ & $421^{3}$ & $410^{1} 42_{1}^{0}$ & 1243 & & $230^{1} 41_{0}^{1} 420^{1}$ \\
\hline 149 & & & $42_{1}{ }^{1}$ & 1271 & & $16_{0}{ }^{1}$ \\
\hline 194 & $410^{2}$ & $420^{6}$ & $410^{2}$ & 1289 & & - \\
\hline 238 & $29_{0}{ }^{1}$ & $290^{1}$ & $29_{0}^{1}$ & 1302 & & $24_{0}^{1} 40_{0}^{1} 41_{0}^{1}$ \\
\hline 283 & $41_{0}{ }^{142} 0^{1}$ & $400^{1} 42_{0}^{1}$ & $410^{1} 420^{1}$ & 1312 & & $230^{14} 40_{0}^{14} 40_{0}^{1}$ \\
\hline 350 & $400^{14} 1_{0}^{1}$ & $\begin{array}{l}39_{0} 1420_{0} 1 \text { or } \\
40_{0} 1420^{3}\end{array}$ & $40_{0} 141_{0} 1$ & 1322 & & $24_{0} 1420^{2}$ \\
\hline 372 & $420^{2}$ & $410^{2}$ & $420^{2}$ & 1345 & & $24_{0}{ }^{1} 28_{0}{ }^{1}$ \\
\hline 395 & $28_{0}{ }^{1}$ & $280^{1}$ & $280^{1}$ & 1357 & & $150^{1}$ \\
\hline
\end{tabular}




\begin{tabular}{|c|c|c|c|c|c|}
\hline 438 & $27_{0}^{1}$ & $\begin{array}{l}410^{2} 420^{2} \text { or } \\
400^{1} 41_{0}{ }^{1}\end{array}$ & $27_{0}^{1}$ & 1379 & $14_{0}^{1}$ \\
\hline 506 & $40_{0}^{2}$ & $400^{2}$ & $40_{0}^{2}$ & 1417 & $13_{0}^{1}$ \\
\hline 518 & $28_{0}{ }^{1} 29_{0}{ }^{1}$ & $290^{1} 40_{0}^{1} 41_{0}^{1}$ & $280^{1} 41_{0}^{1} 42_{0}^{1}$ & 1431 & $11_{0}^{1}$ \\
\hline 524 & & $28_{0} 1420^{4}$ & $26_{0}^{1}$ & 1448 & $240^{1} 40_{0}^{1} 41_{0}^{1}$ \\
\hline 529 & $26_{0}{ }^{1}$ & $27_{0}^{1}$ & $38_{0} 141_{0} 1$ & 1466 & $230_{0} 140_{0}^{2}$ \\
\hline 538 & & $38_{0} 142_{0} 5$ & $40_{0}^{1} 41_{0} 1420^{2}$ & 1475 & $12_{0}{ }^{1}$ \\
\hline 549 & & $280^{1} 420^{5}$ & $400^{1} 410^{3}$ & 1492 & $10_{0}^{1}$ \\
\hline 565 & $410^{2} 420^{2}$ & $400^{2} 420^{2}$ & $410^{2} 420^{2}$ & 1525 & $90^{1}$ \\
\hline 632 & $280^{1} 29_{0} 1$ & $280_{0} 129_{0}^{1}$ & $280_{0}^{1} 29_{0}^{1}$ & 1560 & $180^{1} 40_{0} 141_{0}^{1}$ \\
\hline 681 & $28_{0}^{1} 40_{0}^{14} 41_{0}^{1}$ & $27_{0}^{14} 41_{0}^{142_{1}}{ }^{0}$ & $28_{0}^{1} 40_{0}^{14} 1_{0}^{1}$ & 1569 & - \\
\hline 689 & & & $38_{0} 140_{0} 1$ & 1583 & $\begin{array}{l}180^{1} 42_{0}^{2} \text { or } \\
190^{1} 28_{0}^{1}\end{array}$ \\
\hline 748 & $25_{0}{ }^{1}$ & $25_{0}^{1}$ & $25_{0}^{1}$ & 1607 & $18_{0}^{1} 28_{0} 1$ \\
\hline 873 & & & $270^{2}$ & 1621 & $20_{0}^{1} 26_{0}^{1}$ \\
\hline 921 & & & $26_{0} 128_{0} 1$ & 1638 & $15_{0} 141_{0} 142_{0} 1$ \\
\hline 943 & $22_{0}{ }^{1}$ & $37_{0}^{1} 39_{0}^{1}$ & $25_{0} 141_{0}^{2}$ & 1685 & $10_{0}^{1} 41_{0}^{2}$ \\
\hline 950 & $24_{0}{ }^{1}$ & $24_{0}^{1}$ & $24_{0} 1$ & 1691 & - \\
\hline 961 & $23_{0}{ }^{1}$ & $23_{0}{ }^{1}$ & $23_{0}{ }^{1}$ & 1697 & - \\
\hline 968 & $20_{0}{ }^{1}$ & $35_{0} 139_{0}^{1}$ & $36_{0}^{1} 40_{0}^{1}$ & 1708 & $16_{0}^{1} 27_{0}^{1}$ \\
\hline 974 & & $37_{0}^{1} 380^{1}$ & - & 1715 & $12{ }_{0}^{1} 29_{0} 1$ \\
\hline 983 & $21_{0}^{1}$ & $220^{1}$ & $220^{1}$ & 1729 & $180^{1} 260^{1}$ \\
\hline 998 & & & $25_{0} 129_{0} 1$ & 1778 & $14_{0} 128_{0} 1$ \\
\hline 1031 & $25_{0}{ }^{14} 1_{0} 142_{0}^{1}$ & $21_{0}^{1}$ & $21_{0}{ }^{1}$ & 1813 & $13_{0}{ }^{1} 28_{0}{ }^{1}$ \\
\hline 1045 & & & $260^{2}$ & 1826 & $11_{0}^{1} 28_{0}{ }^{1}$ \\
\hline 1098 & $25_{0}^{1} 40_{0}^{14} 1_{0}^{1}$ & $25_{0} 139_{0} 142_{0}^{1}$ & $20_{0}{ }^{1}$ & 1858 & - \\
\hline 1110 & & & $250^{140} 0^{14} 1_{0}^{1}$ & 1868 & $120_{0}^{1} 28_{0} 1$ \\
\hline 1141 & $25_{0} 126_{0}^{1}$ & $25_{0} 128_{0} 1$ & $25_{0} 128_{0} 1$ & 1896 & $17_{0}{ }^{1} 25_{0}{ }^{1}$ \\
\hline 1149 & $17_{0}^{1}$ & $20_{0}^{1}$ & $17_{0}^{1}$ & 1910 & $240^{2}$ \\
\hline 1187 & & $190^{1}$ & $190^{1}$ & 1922 & $230^{2}$ \\
\hline 1198 & & $23_{0} 129_{0}{ }^{1}$ & $23_{0} 129_{0}{ }^{1}$ & 1958 & $18_{0}^{1} 25_{0}{ }^{1}$ \\
\hline 1211 & $18_{0}{ }^{1}$ & $18_{0}^{1}$ & $18_{0}^{1}$ & & \\
\hline
\end{tabular}

a Reference 27

${ }^{\mathrm{b}}$ Reference 16 
Table 3. Observed styrene peak locations $\left(\mathrm{in}^{-1}\right)$ in the $\mathrm{D}_{0}$ state

Styrene transition excited

\begin{tabular}{|c|c|c|c|c|c|c|c|c|}
\hline Assignments & $0_{0}{ }^{0}$ & $41_{0} 142_{1}^{0}$ & $42_{1}{ }^{1}$ & $410^{2}$ & $29_{0} 1$ & $41_{0}^{14} 2_{0}^{1}$ & $40_{0}{ }^{14} 41_{0}^{1}$ & $28_{0}^{1}$ \\
\hline $0^{0}$ & 0 & & & & & & & \\
\hline $28^{1}$ & 449 & & & & & & & 449 \\
\hline $27^{1}$ & 552 & & & & & & & \\
\hline $26^{1}$ & 645 & & & & & & & \\
\hline $25^{1}$ & 779 & & & & & & & \\
\hline $28^{2}$ & 895 & & & & & & & 892 \\
\hline $24^{1}$ & 983 & & & & & & & \\
\hline $19^{1}$ & 1194 & & & & & & & \\
\hline $18^{1}$ & 1236 & & & & & & & \\
\hline $17^{1}$ & 1303 & & & & & & & \\
\hline $16^{1}$ & 1325 & & & & & & & \\
\hline $15^{1}$ & 1369 & & & & & & & \\
\hline $14^{1}$ & 1410 & & & & & & & \\
\hline $10^{1}$ & 1530 & & & & & & & \\
\hline $9^{1}$ & 1618 & & & & & & & \\
\hline
\end{tabular}

$41^{14} 2_{1}{ }^{0}$

67

$41^{1} 421^{0} 28^{1}$

508

$41^{142} 1^{0} 27^{1}$

618

$421^{1}$

159

$42{ }_{1} 128^{1}$

605

$421^{1} 27^{1}$

713

$41^{2}$

200

$41^{3}$

305

$41^{2} 42^{1}$

381

$41^{2} 28^{1}$

646

$41^{2} 27^{1}$

775

$29^{1}$

254

$29^{2}$

502

$29^{1} 28^{1}$

696 
$41^{1} 42^{1} 28^{1}$

732

$41^{1} 42^{1} 27^{1}$

842

$40^{1}$

359

$40^{1} 41^{1}$

451

$40^{2} 41^{1}$

803

$40^{1} 41^{1} 28^{1}$

901

$28^{2}$

895

$28^{1} 27^{1}$ 


\section{Discussions}

\section{Ionization energy}

For measurement of the IP of styrene, we utilized a number of different ionization wavelengths via $\mathrm{S}_{1}$ $0_{0}{ }^{0}$ origin at $34759 \mathrm{~cm}^{-1}$ in SEVI spectra. The position of the outmost ring associated with the $\mathrm{D}_{0} \leftarrow \mathrm{S}_{1}$ origin transition is plotted versus the photon energy to acquire a linear relationship with respect to each other, as shown in Fig. 5. Extrapolation of the linear fit to the center of the image corresponding to the zero-kinetic energy yields the adiabatic IP, which is estimated to be $68267 \pm 6 \mathrm{~cm}^{-1}(8.46383 \pm 0.000744 \mathrm{eV})$, in good agreement with the $68267 \pm 5 \mathrm{~cm}^{-1}$ value derived from previous ZEKE spectroscopy measurement [31].

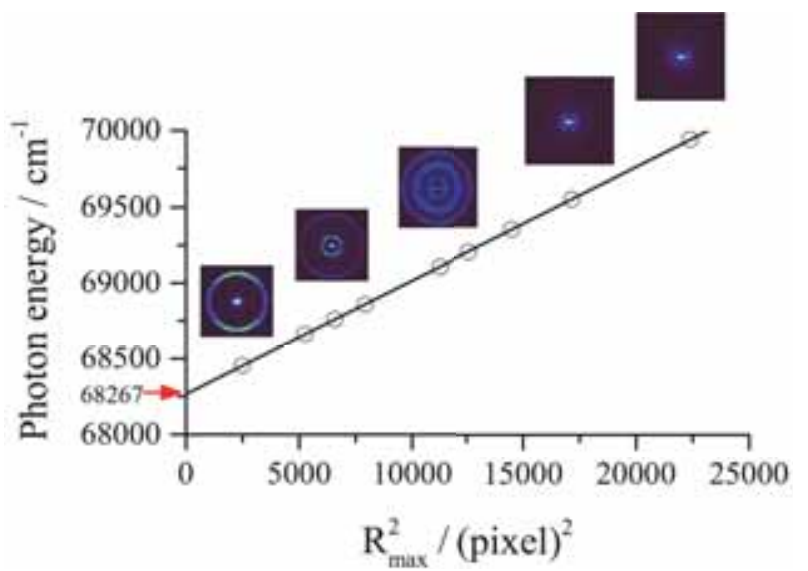

Fig. 5. The total photon energy is plotted against the squares of the radial positions corresponding to the $0^{0}$ peak of the styrene cation. Data points are marked with empty circles. Several photoelectron images are shown together. A linear regression enables the extrapolation of this peak position to zero radius from which the IP denoted by an arrow is deduced.

\section{The vibrational frequencies in the $S_{1}$ state}

Table 2 shows all observed transitions in the 1C-R2PI spectrum and our new assignments compared with the assignments reported by Zilberg et al.[16] and Syage et al. [27]. The frequencies of $v_{42}$ and $v_{41}$ modes in $S_{1}$ are experimentally measured to be 186 and $97 \mathrm{~cm}^{-1}$ by Syage. However, the frequency of 97 $\mathrm{cm}^{-1}$ reported by Zilberg was assigned as $42^{3}$ transition due to their calculation revealing the frequencies of modes 42 and 41 being 33 and $155 \mathrm{~cm}^{-1}$, respectively. There is still a large gap between the experimental values and the calculated ones in $S_{1}$, so some vibrational assignments relevant to the out-of-plane vibrations should be reconsidered.

According to our calculated results, the frequencies of $v_{40}, v_{41}$ and $v_{42}$ modes in $S_{1}$ state are determined to be 255,96 and $191 \mathrm{~cm}^{-1}$, which are in excellent agreement with the reported experimental values [26,27] and our determined ones. There is every reason to believe that the frequency of $97 \mathrm{~cm}^{-1}$ is assigned as mode 41.

According to the vibrational mode analysis provided by Hemley et al. [17], Mode 42 is composed of $75 \% \mathrm{C}_{4}-\mathrm{C}_{7}$ torsion, $10 \%$ ring torsion, $8 \%$ ring out of plane bending and $7 \%$ substituent out of plane bending. $17 \%$ of mode 41 is ascribed to be $\mathrm{C}_{4}-\mathrm{C}_{7}$ torsion while the remaining is $48 \%$ ring torsion and $35 \%$ ring out of plane bending motion. The $\mathrm{C}_{4}-\mathrm{C}_{7}$ torsion component of mode 42 and 41 explains their strong coupling. 
Mode 40 is characterized as $59 \%$ ring torsion, $40 \%$ ring out of plane bending vibration and $1 \% \mathrm{C}_{4}-\mathrm{C}_{7}$ torsion. The same vibrational components of mode 40 and 41 explain the strong coupling of both modes.

The peaks at 529, 689 and $968 \mathrm{~cm}^{-1}$ are assigned to the combination bands $38_{0}{ }^{1} 41_{0}{ }^{1}, 38_{0}{ }^{140} 0_{0}{ }^{1}$, and $36{ }_{0}{ }^{140} 0_{0}{ }^{1}$, respectively. Modes 36 and 38 are related to the out-of-plane $\mathrm{C}_{4}-\mathrm{C}_{7}$ bending with the ring $\mathrm{CH}$ bending. These four modes are strongly coupled because of the motion of $\mathrm{C}_{4}-\mathrm{C}_{7}$. The frequencies of modes 36, 38, 40 and 41 are determined to be 711, 431, 253 and $97 \mathrm{~cm}^{-1}$, respectively. So the assignments of transitions at 529, 689 and $968 \mathrm{~cm}^{-1}$ to the combination bands $38_{0} 141_{0}{ }^{1}, 38_{0} 140_{0}{ }^{1}$ and $36_{0}{ }^{140_{0}}{ }^{1}$ should be reasonable.

The assignments for modes 9-24 of styrene in $S_{1}$ state are conflicting with the previous works. For instance, the frequency of $v_{20}$ is considered to be 967 [20,27], 959 [24], 1114 [26] or 1146 [16] cm- ${ }^{-1}$ Our calculation at TD-B3LYP/6-311++G(d, p) level suggests a possible reassignment of these modes for $\mathrm{S}_{1}$ state. According the calculated results, the frequencies of $v_{24}, v_{23}, v_{22}, v_{21}$ and $v_{19}$ modes in $S_{1}$ state, which were assigned to be 960 [20], 940 [26], 948 [24], 959 [24] and 966 [24] $\mathrm{cm}^{-1}$, are now proposed to be 950, 961, 983, 1031 and $1187 \mathrm{~cm}^{-1}$, respectively. These assignments are in accordance with the Zilberg's assignments[16]. Furthermore, the $v_{0}^{0}+1098 \mathrm{~cm}^{-1}$ transition may be assigned to mode 20 rather than to the $25_{0} 140_{0} 141_{0}^{1}$ [27] and $25_{0} 139_{0}^{1} 42_{0}^{1}$ combination transitions [16].

The combination transitions $25_{0}{ }^{1} 28_{0}{ }^{1}$ and $18_{0}{ }^{1} 28_{0}{ }^{1}$ locate at 1141 and $1607 \mathrm{~cm}^{-1}$ with medium intensity. Mode 25 is related to the in-plane $\mathrm{C}_{4}-\mathrm{C}_{7}$ bending, and mode 28 and 18 are involved in the in-plane $\mathrm{C}_{4}-\mathrm{C}_{7}$ stretching. The frequencies of modes 18, 25 and 28 are measured to be 1208, 748 and $395 \mathrm{~cm}^{-1}$ in $\mathrm{S}_{1}$, so it is reasonable that the peak with a frequency of 1141 and $1607 \mathrm{~cm}^{-1}$ is assigned to the combination transitions $25_{0} 128_{0}^{1}$ and $18_{0}{ }^{1} 28_{0}{ }^{1}$, respectively.

\section{The vibrational frequencies in the $D_{0}$ state}

Frequencies of transitions $29^{1}, 28^{1}, 25^{1}$, and $18^{1}$ relevant to the in-plane $\mathrm{C}_{4}-\mathrm{C}_{7}$ motion along with ring stretching vibrations are measured to be $254,449,779$, and $1236 \mathrm{~cm}^{-1}$ for styrene cation in the $\mathrm{D}_{0}$ state. The corresponding frequencies of these normal modes are measured to be $237,395,748$, and $1211 \mathrm{~cm}^{-1}$ for the molecule in the neutral vibronic excited $S_{1}$ state. Clearly, frequencies of these vibrations of this molecule in the $\mathrm{D}_{0}$ state are slightly higher than those in the $\mathrm{S}_{1}$ state. An interpretation is that the molecular geometry of styrene along these canonical coordinates is slightly more rigid in the cationic $\mathrm{D}_{0}$ state than that in the neutral $S_{1}$ state as supported by theoretical prediction.

Mode 27 and 16 are related to the in-plane double bond bending vibration. In the 1C-R2PI spectrum mode 27 and 16 are weak transitions at 438 and $1271 \mathrm{~cm}^{-1}$, whereas in the SEVI spectra, they correspond to the strong transitions at 552 and $1325 \mathrm{~cm}^{-1}$. Mode 9 (in-plane double bond stretching with $\mathrm{C}_{4}-\mathrm{C}_{7}$ bending) is observed as a medium peak at $1525 \mathrm{~cm}^{-1}$ in the 1C-R2PI spectrum, but strongly appears in the SEVI spectra 
at $1618 \mathrm{~cm}^{-1}$. The motion of double bond is not obvious in the excited state with the antibonding $\pi$ electron, nevertheless the Franck-Condon overlap of these three modes become larger due to the removal of $\pi^{*}$ electron.

Mode 42 is related to the $\mathrm{C}_{4}-\mathrm{C}_{7}$ single bond torsion vibration. Mode 42 has a frequency of $188 \mathrm{~cm}^{-1}$ in the cation, which is representing little change from the first excited state of $186 \mathrm{~cm}^{-1}$ but more than $38 \mathrm{~cm}^{-1}$ in the ground state. Removing the $\pi^{*}$ electron does not affect the interaction of the vinyl group with the ring. The frequencies of mode 41 corresponding to the $\mathrm{C}_{4}-\mathrm{C}_{7}$ single bond bending decrease from $213 \mathrm{~cm}^{-1}$ in the $S_{0}$ state to $97 \mathrm{~cm}^{-1}$ in $S_{1}$. The SEVI spectra reveal that the frequency of cation is $100 \mathrm{~cm}^{-1}$. The frequencies of the $S_{1}$ and $D_{0}$ state are close but much lower than the $S_{0}$ state, indicating that the molecular geometry of styrene is more rigid with the $\pi$ electron. Mode 40 is involved in the out-of-plane ring deformation. It is found to have a frequency of $359 \mathrm{~cm}^{-1}$ in the ground state of cation, which is between the excited state frequency of $253 \mathrm{~cm}^{-1}$ and the ground state frequency of $422 \mathrm{~cm}^{-1}$. The antibonding $\pi$ electron makes the ring more flexible.

\section{Photoelectron Angular Distribution}

The photoelectron angular distribution (PAD) is obtained by integrating the intensity of the Abelinverted image. The PADs in two-photon ionization with linearly polarized light are generally described by the function: $[38,39]$

$$
I(\theta)=k\left[1+\beta_{2} P_{2}(\theta)+\beta_{4} P_{4}(\theta)\right],
$$

where $\theta$ is the angle between the electron velocity vector and the laser polarization direction in the laboratory frame, $k$ is a normalization constant proportional to the total photoionization cross-section, and $P_{2}$ and $P_{4}$ are the second-order and fourth-order Legendre polynomials. The angular dependence is completely defined by $\beta$, the anisotropy parameter, which can be determined by fitting Eq. (1) to the experimental PAD.

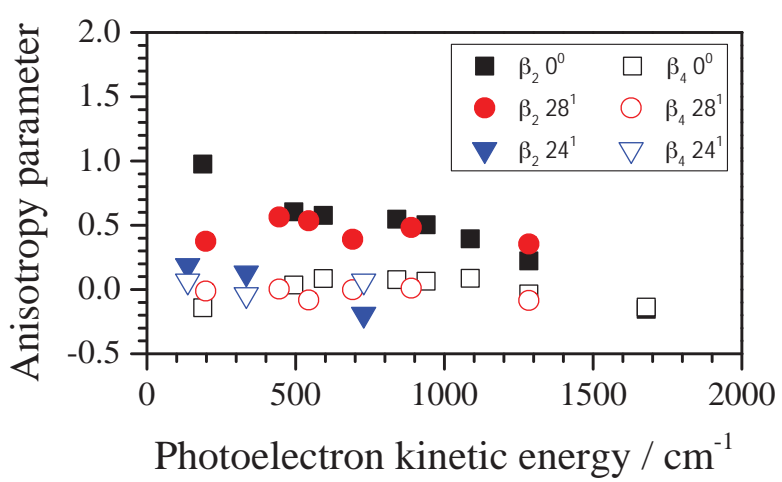

Fig. 6. The photoelectron angular anisotropy parameters $\left(\beta_{2}\right.$ and $\left.\beta_{4}\right)$ obtained from the images pumping by $\mathrm{S}_{1} 0_{0}{ }^{0}$ level shown in Fig. 2 as a function of PKE. The solid and hollow symbols indicate $\beta_{2}$ and $\beta_{4}$ values, respectively. Different symbols represent the values obtained for different vibronic states in the $\mathrm{D}_{0}$ state.

The PAD is determined by a photoelectron scattering wave that varies with the photoelectron kinetic 
energy (PKE) and the vibronic state of the cation upon ionization. The values of $\beta_{2}$ and $\beta_{4}$ following excitation of $S_{1} 0_{0}{ }^{0}$ vary with PKE displayed in Fig. 6 . The graph shows that the $\beta_{2}$ decreases slowly with the increase of PKE and gently fell into negative value within $1700 \mathrm{~cm}^{-1}$ above the ionization threshold; however the $\beta_{4}$ values vacillate near zero. All values of $\beta_{2}$ and $\beta_{4}$ are available in Table S4.

PAD studies of difluorobenzene isomers [40-42] and our previous work for aniline [43] all suggest that the decrease of $\beta_{2}$ parameter is dramatic with the increase of PKE. This behavior is believed to be a near threshold shape resonance taking place in the ionization due to the virtual $\pi^{*}$ antibonding orbital mainly concentrated on the benzene ring $[41,42]$. However the virtual $\pi^{*}$ antibonding orbital of styrene extends to the vinyl group under the influence of $\mathrm{C}-\mathrm{C}$ double bond [5]. Based on above analysis, there is no observable near threshold shape resonance detected in the case of styrene.

\section{Conclusion}

The energies, geometries, and vibrational frequencies of styrene in $S_{1}$ and $D_{0}$ states are studied in detail by the R2PI and SEVI techniques in combination with the high-level theoretical calculations. The neural ground state appears to be planar with the B3LYP/6-311++G(d, p) level calculation. The predicted vibrational frequencies agree well with the experiment results. For $S_{1}$ state, the planar feature is revealed under the theoretical calculation at TD-B3LYP/6-311++G(d,p) level. With the $\pi^{*} \leftarrow \pi$ excitation, the benzene ring is expanded unsymmetrically and the double bond is lengthened a bit, whereas the length of $\mathrm{C}_{4}-\mathrm{C}_{7}$ bond decreases. The interaction of the vinyl group with the ring is enhanced. The 1C-R2PI spectrum of styrene gives the $\mathrm{S}_{1} \leftarrow \mathrm{S}_{0}$ electron transition energy, $34729 \pm 3 \mathrm{~cm}^{-1}$. Most low-frequency vibrations are unambiguously identified with the aid of calculated results. Some controversially high-frequency vibrational modes are reassigned in comparison of theoretical results. In the 2C-R2PI SEVI spectra, the accurate IP is obtained to be $68267 \pm 6 \mathrm{~cm}^{-1}$. The SEVI spectra taken via various $\mathrm{S}_{1}$ intermediate states provide accurate vibrational frequencies of styrene in cationic ground state. The vibrational frequencies of the $\mathrm{D}_{0}$ state calculated at the B3LYP/6-311++G(d, p) level are in excellent agreement with the experimental results to aid in assigning some high-frequency modes.

\section{Acknowledgements}

This work is supported by the National Science Foundation of China (Grant No. 21503003, 11674003, and 61475001), Anhui Natural Science Foundation (Grant No. 1608085QA10), and Anhui University Natural Science Foundation (Grant No. KJ2015A032). We also acknowledge additional support from Special Program for Applied Research on Super Computation of the NSFC-Guangdong Joint Fund (the second phase). 


\section{References}

[1] W. C. Teach and G. C. Kiessling, Polystyrene. (Reinhold, Chapman \& Hall, 1960) .

[2] M. Hallquist, J. C. Wenger, U. Baltensperger, Y. Rudich, D. Simpson, M. Claeys, J. Dommen, N. M. Donahue, C. George, A. H. Goldstein, J. F. Hamilton, H. Herrmann, T. Hoffmann, Y. Iinuma, M. Jang, M. E. Jenkin, J. L. Jimenez, A. KiendlerScharr, W. Maenhaut, G. McFiggans, T. F. Mentel, A. Monod, A. S. H. Prévôt, J. H. Seinfeld, J. D. Surratt, R. Szmigielski and J. Wildt, Atmos. Chem. Phys. 9 (2009) 5155.

[3] W. J. Li, D. Z. Zhang, L. Y. Shao, S. Z. Zhou and W. X. Wang, Atmos. Chem. Phys. 11 (2011) 11733.

[4] E. C. Tuazon, J. Arey, R. Atkinson and S. M. Aschmann, Environ. Sci. Technol. 27 (1993) 1832.

[5] A. D. G. Nunn, R. S. Minns, R. Spesyvtsev, M. J. Bearpark, M. A. Robb and H. H. Fielding, Phys. Chem. Chem. Phys. 12 (2010) 15751.

[6] H. Suzuki, B. Chem. Soc. Jpn. 33 (1960) 619.

[7] V. H. Grassian, E. R. Bernstein, H. V. Secor and J. I. Seeman, J. Phys. Chem. 93 (1989) 3470.

[8] K. L. Facchine, S. W. Staley, P. C. M. Van Zijl, P. K. Mishra and A. A. Bothner-By, J. Am. Chem. Soc. 110 (1988) 4900.

[9] D. A. Condirston and J. D. Laposa, J. Mol. Spectrosc. 63 (1976) 466.

[10] A. Marchand and J.-P. Quintard, Spectrochim. Acta. A 36 (1980) 941.

[11] P. Borowski, M. Fernández-Gómez, M.-P. Fernández-Liencres, T. P. Ruiz and M. Q. Rincón, J. Mol. Struct. 924-926 (2009) 493.

[12] J. M. Granadino-Roldán, M. Fernández-Gómez and A. Navarro, Chem. Phys. Lett. 372 (2003) 255.

[13] P. L. Britton, C. L. Cheng, R. J. W. Le Fevre, L. Radom and G. L. D. Ritchie, J. Chem. Soc. B (1971) 2100.

[14] M. Head-Gordon and J. A. Pople, J. Phys. Chem. 97 (1993) 1147.

[15] S. Tsuzuki, K. Tanabe and E. Osawa, J. Phys. Chem. 94 (1990) 6175.

[16] S. Zilberg and Y. Haas, J. Chem. Phys. 103 (1995) 20.

[17] R. J. Hemley, D. G. Leopold, V. Vaida and M. Karplus, J. Chem. Phys. 82 (1985) 5379.

[18] R. J. Hemley, U. Dinur, V. Vaida and M. Karplus, J. Am. Chem. Soc. 107 (1985) 836.

[19] O. Dimopoulou-Rademann, U. Even, A. Amirav and J. Jortner, J. Phys. Chem. 92 (1988) 5371.

[20] L. Chia, L. Goodman and J. G. Philis, J. Chem. Phys. 79 (1983) 593.

[21] J. I. Seeman, V. H. Grassian and E. R. Bernstein, J. Am. Chem. Soc. 110 (1988) 8542.

[22] J. G. Philis, A. Ioannidou and A. A. Christodoulides, J. Mol. Spectrosc. 174 (1995) 51.

[23] J. M. Hollas and T. Ridley, Chem. Phys. Lett. 75 (1980) 94.

[24] J. M. Hollas and T. Ridley, J. Mol. Spectrosc. 89 (1981) 232.

[25] J. M. Hollas, H. Musa, T. Ridley, P. H. Turner, K. H. Weisenberger and V. Fawcett, J. Mol. Spectrosc. 94 (1982) 437.

[26] J. M. Hollas, E. Khalilipour and S. N. Thakur, J. Mol. Spectrosc. 73 (1978) 240.

[27] J. A. Syage, F. Al Adel and A. H. Zewail, Chem. Phys. Lett. 103 (1983) 15.

[28] J. W. Ribblett, D. R. Borst and D. W. Pratt, J. Chem. Phys. 111 (1999) 8454.

[29] G. L. Bendazzoli, G. Orlandi, P. Palmieri and G. Poggi, J. Am. Chem. Soc. 100 (1978) 392.

[30] G. Orlandi, P. Palmieri and G. Poggi, J. Chem. Soc., Faraday Trans. 277 (1981) 71.

[31] J. M. Dyke, H. Ozeki, M. Takahashi, M. C. R. Cockett and K. Kimura, J. Chem. Phys. 97 (1992) 8926.

[32] J. M. Smith and J. L. Knee, Laser Chem. 14 (1994) 131.

[33] C. J. Hammond and K. L. Reid, Phys. Chem. Chem. Phys. 10 (2008) 6762.

[34] Z. Qu, C. Li, Z. Qin, X. Zheng, G. Yao, X. Zhang and Z. Cui, Rev. Sci. Instrum. 86 (2015) 063106.

[35] V. Dribinski, A. Ossadtchi, V. A. Mandelshtam and H. Reisler, Rev. Sci. Instrum. 73 (2002) 2634.

[36] M. Valiev, E. J. Bylaska, N. Govind, K. Kowalski, T. P. Straatsma, H. J. J. Van Dam, D. Wang, J. Nieplocha, E. Apra, T. L. Windus and W. A. de Jong, Comput. Phys. Commun. 181 (2010) 1477.

[37] T. Yanai, D. P. Tew and N. C. Handy, Chem. Phys. Lett. 393 (2004) 51.

[38] C. N. Yang, Phys. Rev. 74 (1948) 764.

[39] Y. Ogi, H. Kohguchi, D. Niu, K. Ohshimo and T. Suzuki, J. Phys. Chem. A 113 (2009) 14536.

[40] S. M. Bellm and K. L. Reid, Phys. Rev. Lett. 91 (2003) 263002.

[41] S. M. Bellm, J. A. Davies, P. T. Whiteside, J. Guo, I. Powis and K. L. Reid, J. Chem. Phys. 122 (2005) 224306.

[42] M. Staniforth, S. Daly, K. L. Reid and I. Powis, J. Chem. Phys. 139 (2013) 064304.

[43] Z. Qu, Z. Qin, X. Zheng, H. Wang, G. Yao, X. Zhang and Z. Cui, Spectrochim. Acta. A 173 (2017) 432. 